\title{
Bmi-1 induces radioresistance in MCF-7 mammary carcinoma cells
}

\author{
ZHI-GANG LIU ${ }^{1,2}$, LI LIU $^{1}$, LI-HUA XU ${ }^{1,3}$, WEI YI ${ }^{1,2}$, YA-LAN TAO ${ }^{1,2}$, \\ ZI-WEI TU ${ }^{1,2}$, MAN-ZHI LI ${ }^{1,3}$, MU-SHENG ZENG ${ }^{1,3}$ and YUN-FEI XIA ${ }^{1,2}$ \\ ${ }^{1}$ State Key Laboratory of Oncology in Southern China; Departments of ${ }^{2}$ Radiation Oncology, and \\ ${ }^{3}$ Experimental Research, Sun Yat-sen University Cancer Center, Guangzhou 510060, P.R. China
}

Received October 24, 2011; Accepted November 22, 2011

DOI: $10.3892 /$ or.2011.1615

\begin{abstract}
Bmi-1, a member of the polycomb family, it is involved in self renewal of stem cells and functions as an oncogene in many malignant human cancer types. Recent studies have demonstrated that Bmi-1 is a predictive factor for poor patient prognosis. However, the underlying mechanisms of radioresistance mediated by Bmi-1 are poorly understood. In this study, the dose-survival relationship was analyzed using a clonogenic survival assay and combined radiation treatment with Bmi-1 overexpression or silencing. DNA double-strand break (DSB) and repair was assessed by immunofluorescence staining of $\gamma \mathrm{H} 2 \mathrm{AX}$ foci. In addition, mitochondrial membrane potential was detected between Bmi-1 knockdown and control MCF-7 cells after irradiation. Apoptosis and cell cycle were evaluated by flow cytometry. We found that exposure of MCF-7 cells overexpressing Bmi-1 to ionizing radiation resulted in dramatically enhanced survival relative to control cells, whereas cells with silenced Bmi-1 showed markedly reduced survival. Bmi-1 inhibition significantly increased DSBs and decreased DSB repair. Furthermore, Bmi-1 knockdown induced loss of mitochondrial membrane potential and enhanced apoptosis by up-regulating p53, $\mathrm{p} 21$, Bax expression and down-regulating $\mathrm{p}-\mathrm{AKT}$ and $\mathrm{Bcl}-2$
\end{abstract}

Correspondence to: Dr Yun-Fei Xia, State Key Laboratory of Oncology in Southern China and Department of Radiation Oncology, Sun Yat-sen University Cancer Center, Guangzhou 510060, P.R. China

E-mail: xiayf@sysucc.org.cn

Dr Mu-Sheng Zeng, State Key Laboratory of Oncology in South China and Department of Experimental Research, Sun Yat-sen University Cancer Center, Guangzhou 510060, P.R. China

E-mail: zengmsh@sysucc.org.cn

Abbreviations: Bmi-1, B-cell-specific moloney murine leukemia virus integration site 1; EMT, epithelial-mesenchymal transition; DSB, DNA double strand break; KD, knock down; GSK3 $\beta$, glycogen synthase kinase $3 \beta$; Akt, protein kinase B

Key words: Bmi-1, radioresistance, mammary carcinoma cells expression. These results indicate that Bmi-1 may play an important role in radiosensitivity, and the suppression of its expression might be a potential therapeutic target for breast cancer.

\section{Introduction}

Polycomb group (PcG) proteins, which are known to maintain the silenced state of homeotic genes, are important for constituting a cellular memory system responsible for maintaining the epigenetic status of target genes throughout the lifetime of the organism $(1,2)$. PcG proteins play a crucial role in many physiological processes, such as germline development, cell differentiation, pluripotency and stem cell self-renewal $(3,4)$. $\mathrm{PcG}$ proteins form transcriptional repressor modules that functionally can be divided into at least three distinct classes of complexes: polycomb repression complex 1 (PRC1), including RING1A, HPC1-3, HPH1-3, and Bmi-1, is to maintain repression; PRC2, with the core proteins EZH2, EED, and SUZ12, is to inhibit gene expression directly. Both PRC1 and PRC2 members have been found involved in malignant transformation and tumor development in various hematological and epithelial cancers (5).

B-cell-specific moloney murine leukemia virus integration site 1 (Bmi-1) is a member of PRC1 that was initially identified as an oncogene involved in the development of mouse pre B-cell lymphoma cooperating with c-Myc $(6,7)$. Many studies have demonstrated that Bmi-1 protein regulates the INK4a/ARF locus, which encodes the two tumor suppressors, p16 ${ }^{\text {INK4a }}$ and $\mathrm{p} 14^{\mathrm{ARF}}$ ( $\mathrm{p} 19^{\mathrm{ARF}}$ in mouse), which act in $\mathrm{pRb}$ and $\mathrm{p} 53$ cell cycle control pathways, respectively $(8,9)$. Bmi-1 promotes cellular proliferation by repression the expression of the INK4a/ARF locus (9). Moreover, overexpression of Bmi-1 in epithelial cells could induce human telomerase reverse transcriptase activity, which is associated with cell immortalization $(10,11)$. It has also been shown that Bmi-1 overexpression together with $\mathrm{H}-\mathrm{Ras}$ promotes human mammary epithelial cell (HMEC) transformation and breast oncogenesis (12). Interestingly, Bmi-1 has been recently shown to play a crucial role in self renewal of hematopoietic and neural stem cells and leukemic stem cells (13-15). Previous studies also showed that Bmi-1 plays important roles in regulating self-renewal of normal and tumorigenic human mammary stem cells (16). 
In clinical study, overexpression of Bmi-1 has been correlated with cancer susceptibility and poor prognosis in several human cancers, including non-small cell lung cancer (17), gastric carcinoma (18), hepatocellular carcinoma (19), acute myeloid leukemia (20), breast cancer (21), nasopharyngeal carcinoma (22), and bladder cancer (23). Furthermore, Bmi-1-associated gene expression pathway, which is 11 gene Bmi-1 stem cell signature, is a powerful predictor of a short interval to distant metastasis, highly malignant clinical course of disease progression, and high likehood of therapy failure in multiple types of human cancer (24). Epithelialmesenchymal transition (EMT), epithelial cells acquire mesenchymal-like properties, which increase cell motility, and EMT generates cells with properties of stem cells (25). Bmi-1 is essential in EMT process $(22,26,27)$, and EMT also mediates radioresistance in human cancer cells $(28,29)$. Our previous study demonstrated that Bmi-1 promotes the invasion and metastasis of human breast cancer and predicts poor survival, the inhibition of Bmi-1 reverses the expression of EMT markers and inhibits the Akt/GSK3 $3 /$ Snail pathway (30). These observations led us to hypothesize that abrogation of Bmi-1 expression could be a potential therapeutic strategy against human cancers. We hypothesized that Bmi-1 inhibition combined radiotherapy could induce synergistic effect on MCF-7 tumor cells. We tested this hypothesis by evaluating the effects of Bmi-1 inhibition by shRNA on DNA damage, apoptosis, mitochondrial membrane potential $(\Delta \Psi \mathrm{m})$ and apoptosis related protein for the purpose of a more improved cancer therapy.

\section{Materials and methods}

Cell culture. MCF-7 (human breast cancer) cell line was obtained from the American Type Culture Collection (ATCC, Manassas, VA) and incubated in DMEM (Invitrogen, Carlsbad, CA) supplemented with $10 \%$ fetal bovine serum (FBS; Hyclone, Logan, UT), penicillin (100 units $/ \mathrm{ml}$ ), and streptomycin $(100$ units $/ \mathrm{ml})$ at $37^{\circ} \mathrm{C}$ in humidified $5 \% \mathrm{CO}_{2}$ incubator.

Generation of stable Bmi-1 overexpression and Bmi-1 knockdown (KD) cell lines. Retroviral vector pMSCV-Bmi-1 and Bmi-1 short hairpin RNA (shRNA) was previously described $(22,28)$. Retroviruses were generated by transients transfection as described (31). Bmi-1 gene was introduced into MCF-7 cells by infecting cells with a retroviral vector pMSCV-Bmi-1 or pMSCV-Bmi-1-shRNA (knockdown, KD). Control cells were infected with the empty retroviral vector pMSCV. Retrovirusinfected were selected and maintained in $0.5 \mu \mathrm{g} / \mathrm{ml}$ puromycin for 7 days and used as stable cells.

Radiation clonogenic survival assay. Cells were seeded in triplicate into 60-mm culture dishes in a range of 100-10,000 cells per dish, depending on the radiation dose that the cells received and the test condition, so as to yield 0-100 colonies per dish. Cells were then irradiated with a single dose of $\mathrm{X}$ ionizing radiation (irradiation rate of $104.93 \mathrm{cGy} / \mathrm{min}$ at $210 \mathrm{kV}$ and $12 \mathrm{~mA}$ ) (32), including $0,1,2,4$ and 6 Gy. Immediately after irradiation, the treated cells were cultured in a $37^{\circ} \mathrm{C}, 5 \% \mathrm{CO}_{2}$ incubator for 10-14 days. Individual colonies ( $>50$ cells per colony) were fixed with methanol and stained with crystal violet. Plating efficiency (PE) and survival fractions (SF) were calculated. Survival curves were fitted and analyzed using linear-quadratic model $\left[S=\exp \left(-\alpha \mathrm{D}-\beta \mathrm{D}^{2}\right)\right]$ by GraphPad Prism software (version 4.0, GraphPad Prism software, San Diego, CA). The radiation sensitizing enhancement ratio (SER) by Bmi-1 inhibition was calculated using the following formula: $\mathrm{SER}=\left(\mathrm{SF}_{2}\right.$ of MCF-7 infected by control vector $) /\left(\mathrm{SF}_{2}\right.$ of Bmi-1-overexpressing MCF-7 or Bmi-1-silencing MCF-7). SER $=1$ suggests an additive radiation effect and SER $>1$, a supra-additive effect as against a sub-additive effect in the case of SER $<1$.

Immunofluorescence staining. Cells were seeded on coverslips in 6-well plates and allowed to grow overnight. Cells were irradiated with a single dose of $0,1,2,4$ and 6 Gy. After $15 \mathrm{~min}$, cells was washed and fixed with $4 \%$ paraformaldehyde. Or cells were fixed at designed measuring time $(0,15,30 \mathrm{~min}, 1$, 3,6 and $20 \mathrm{~h}$ ) after irradiated with a single dose of $5 \mathrm{~Gy}$. Then, cells were rinsed in phosphate-buffered saline (PBS). After blocking in $10 \%$ normal blocking serum at room temperature for $10 \mathrm{~min}$, slides were incubated with $\gamma \mathrm{H} 2 \mathrm{AX}$ antibody (Cell Signaling Technology, Beverly, MA) at $4^{\circ} \mathrm{C}$ overnight and then incubated with goat anti-rabbit $\operatorname{IgG}$ conjugated with FITC (Molecular Probe, Carlsbad, CA). Slides mounted with Prolong Gold antifade reagent with DAPI (Molecular Probe) and examined by fluorescence microscopy (Carl Zeiss Axioskop 2, Thornwood, NY). Cells were judged as 'positive' for $\gamma \mathrm{H} 2 \mathrm{AX}$ foci when they displayed 10 or more discrete dots of brightness. For quantitation of foci, a minimum of 100 cells were analyzed for each time point. All data points represent mean $\pm \mathrm{SD}$ of three experiments.

FACS analysis. After 8 Gy irradiation, cells were harvested at designed measuring time (0,3, 5 and 7 days) and fixed with $70 \%$ ice-cold ethanol. Cells were treated with RNase A $(50 \mu \mathrm{g} / \mathrm{ml}$, Sigma-Aldrich, St. Louis, MO) and stained with propidiumiodide (PI, $50 \mu \mathrm{g} / \mathrm{ml}$, Sigma-Aldrich). The fluorescence of DNA-bound PI in cells was measured with FACSCalibur Flow Cytometer (Becton-Dickinson, Franklin Lakes, CA).

Measurement of mitochondrial membrane potential $(\Delta \Psi m$. Mitochondrial membrane potential was measured using the mitochondrial-specific dual-fluorescence probe, JC-1, based on the method previously described (33). Cells were irradiated with 0 or $5 \mathrm{~Gy}$. After $24 \mathrm{~h}$, cells were incubated with the $10 \mu \mathrm{g} / \mathrm{ml} \mathrm{JC}-1$ for $10 \mathrm{~min}$ followed by two wash with PBS. A CytoFluor plate reader (excitation wavelength $485 \mathrm{~nm}$, slit width $20 \mathrm{~nm}$ ) was used to monitor the fluorescence intensities for the monomer and the aggregated JC-1 molecules (emission wavelength $520 \mathrm{~nm}$, slit width of $25 \mathrm{~nm}$, and $580 \mathrm{~nm}$, slit width of $30 \mathrm{~nm}$, respectively). Results were expressed as fluorescence ratio $(580 / 530 \mathrm{~nm})$.

Western blot analysis. Cells were washed in cold phosphatebuffered saline (PBS) and lysed in a RIPA buffer containing $50 \mathrm{mM}$ Tris- $\mathrm{HCl} \mathrm{pH} 7.4,150 \mathrm{mM} \mathrm{NaCl}, 1 \mathrm{mM}$ PMSF, $1 \mathrm{mM}$ EDTA, $5 \mu \mathrm{g} / \mathrm{ml}$ aprotinin, $5 \mu \mathrm{g} / \mathrm{ml}$ leupeptin, $1 \%$ Triton X-100, $1 \%$ sodium deoxycholate and $0.1 \%$ SDS. The 
A

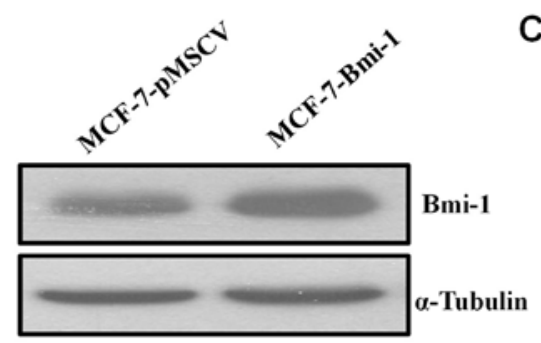

C

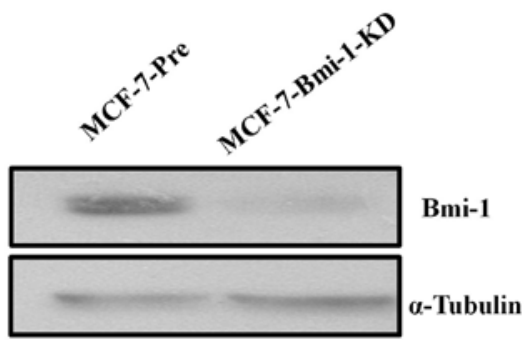

B

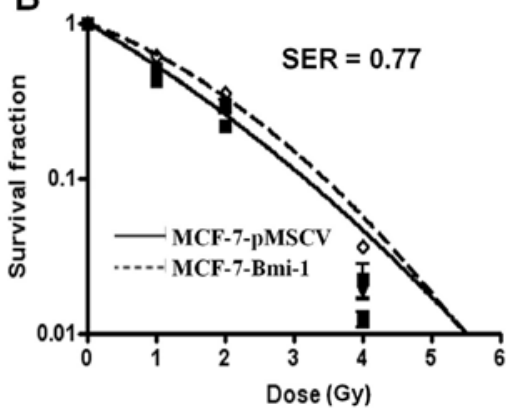

D

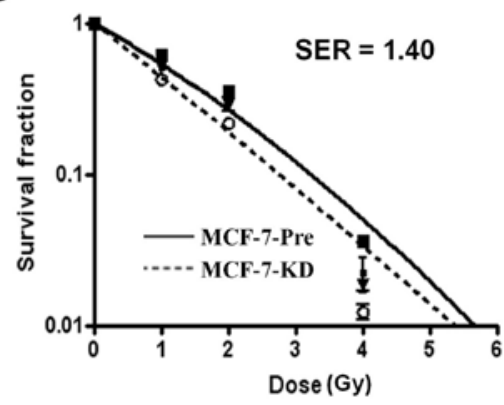

Figure 1. Bmi-1 regulates radiosensitivity in MCF-7 cell line. (A) Western blot analysis performed on pMSCV control vector and expressing Bmi-1 using antiBmi-1, and anti- $\alpha$-tubulin antibodies. (B) Increased expression of Bmi-1 enhances resistance to radiotherapy. P=0.007; ANOVA test (C) Western blot analysis performed on shBmi-1 or vector cells using anti-Bmi-1, and anti- $\alpha$-tubulin antibodies. (D) Down-regulation of Bmi-1 increase the sensitivity of MCF-7 cells to irradiation. $\mathrm{P}<0.001$; ANOVA test.

protein concentration was determined by the Bradford dye method (Bio-Rad Laboratories, Hercules, CA). Equal amounts of cell extract were subjected to electrophoresis in $10 \%$ or $15 \%$ SDS-PAGE and transferred to polyvinylidene difluoride membranes (Amersham Pharmacia Biotech, Piscataway, NJ). The membrane was probed with primary antibody overnight, subsequently incubated with horseradish peroxidase-conjugated anti-rabbit or anti-mouse immunoglobulin G (1:2000; Santa Cruz Biotechnology, Santa Cruz, CA) and detected by enhanced chemiluminescence (Amersham Pharmacia Biotech) according to the manufacturer's suggested protocols. Mouse anti-Bmi-1 (F6) antibody was from Upstate Biotechnical (Lake Placid, NY), rabbit anti-phosphorylated Akt (Ser473) antibody were from Cell Signaling, and mouse anti-p53 (DO-1), mouse anti-p21 (F-5), mouse anti-Bax (6A7), Bcl-2 (C-2), mouse anti$\alpha$-tubulin antibodies were from Santa Cruz Biotechnology.

Statistical analysis. Statistical analysis was performed using Student's t-test or ANOVA test by SPSS 12.0 software (Abbott Laboratories, North Chicago, IL). Differences were considered statistically significant at $\mathrm{P}<0.05$. We performed each study at least three times under identical conditions.

\section{Results}

Bmi-1 expression is associated with radiation response of MCF-7 cells. We first studied whether Bmi-1 overexpression was correlated with radiosensitivity of MCF-7 cells. For this purpose, we infected MCF-7 cells with a retroviral vector expressing Bmi-1 or pMSCV control vector. After puromycin selection, overexpression of Bmi-1 was confirmed by Western blot analysis (Fig. 1A). By classical radiation clonogenic survival assay, we found that Bmi-1-overexpressing cells (MCF-7-Bmi-1) had more radioresistance and higher survival than pMSCV vector infected (MCF-7-pMSCV) cells $(\mathrm{F}=4.183, \mathrm{P}=0.007$; ANOVA test) (Fig. 1B). Statistical analysis of the survival parameters calculated using the linear-quadratic model revealed that there was a significant difference in the $\alpha$ value, characterizing the initial slope of the curving radiation survival curve fitted to all the data from the three repeat experiments as a function of dose, between MCF-7-Bmi-1 cells $\left(\alpha=0.380 \pm 0.039 \mathrm{~Gy}^{-1}\right)$ and MCF-7-pmscv cells $\left(\alpha=0.588 \pm 0.054 \mathrm{~Gy}^{-1}\right)(\mathrm{P}<0.05)$. Bmi-1 overexpression enhanced radiation resistance by $\mathrm{SER}=0.77\left(\mathrm{SF}_{2}=0.257\right.$ for MCF-7-pMSCV cells; $\mathrm{SF}_{2}=0.333$ for MCF-7-Bmi-1 cells).

Next, we asked whether silencing of Bmi-1 expression by RNA interference (RNAi) was able to increase the sensitivity of MCF-7 cells to irradiation. As expected, Bmi-1 shRNAexpressing cells (MCF-7-KD cells) exhibited significantly enhanced radiosensitivity compared with control vector infected cells (MCF-7-Pre cells) $(\mathrm{F}=4.183, \mathrm{P}<0.001$; ANOVA test) (Fig. 1C and D). Statistical analysis of the survival parameters calculated using the linear-quadratic model also revealed a significant sensitization effect. The $\alpha$ value for MCF-7-KD and MCF-7-Pre cells was $0.814 \pm 0.056$ and $0.580 \pm 0.041 \mathrm{~Gy}^{-1}$, respectively. Bmi-1 inhibition enhanced radiosensitivity by $\mathrm{SER}=1.40\left(\mathrm{SF}_{2}=0.264\right.$ for MCF-7-Pre cells; $\mathrm{SF}_{2}=0.189$ for MCF-7-KD cells). Thus, these data suggested that Bmi-1 might be a critical regulator in radiation response in MCF-7 cells.

Increased DNA double strand break (DSB) and decreased $D S B$ repair caused by Bmi-1 silencing. Phosphorylated histone $\mathrm{H} 2 \mathrm{AX}(\gamma \mathrm{H} 2 \mathrm{AX})$ foci measurement, a more sensitive detecting method of DNA DSBs, was used to verify further this increase DNA DSBs after Bmi-1 silencing. As shown in Fig. 2A and $\mathrm{B}$, by $15 \mathrm{~min}$ after $1 \mathrm{~Gy}, 36.0 \%$ of MCF-7-Pre cells demonstrated $\gamma \mathrm{H} 2 \mathrm{AX}$ foci compared with $62.3 \%$ of MCF-7-KD cells ( $\mathrm{P}=0.001$; t-test). At $2 \mathrm{~Gy}, 72.0 \%$ of MCF-7-Pre cells and 
A

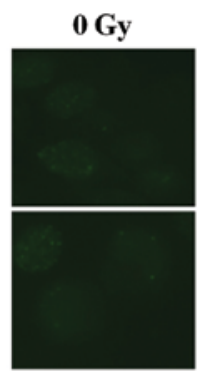

$1 \mathbf{G y}$

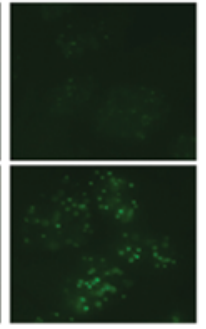

2 Gy
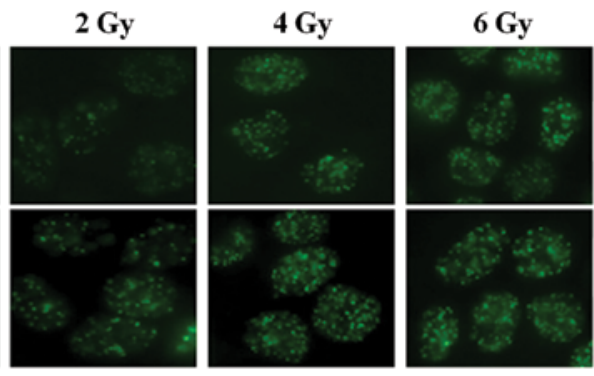

15 min later

MCF-7-Pre

B

C
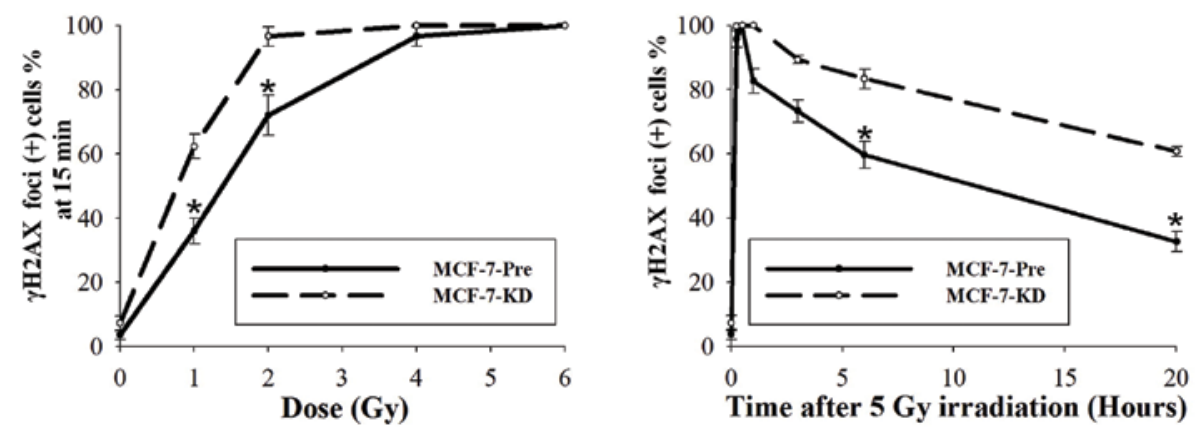

Figure 2. Bmi-1 knockout delayed DNA damage repair in MCF-7 cell line. (A) Graph showing $\gamma \mathrm{H} 2 \mathrm{AX}$ foci in Bmi-1-depleted MCF-7 cells vs. control 5 min later after irradiation. Original magnification, $\mathrm{x} 600$. (B) $\gamma \mathrm{H} 2 \mathrm{AX}$ foci positive cells after different dose irradiation. Mean \pm SD of three experiments are reported. (C) $\gamma \mathrm{H} 2 \mathrm{AX}$ foci positive cells at different time point after $5 \mathrm{~Gy}$ irradiation between MCF-7-control cells and MCF-7-knockout cells. ${ }^{*} \mathrm{P}<0.001$; $\mathrm{t}$-test.

A
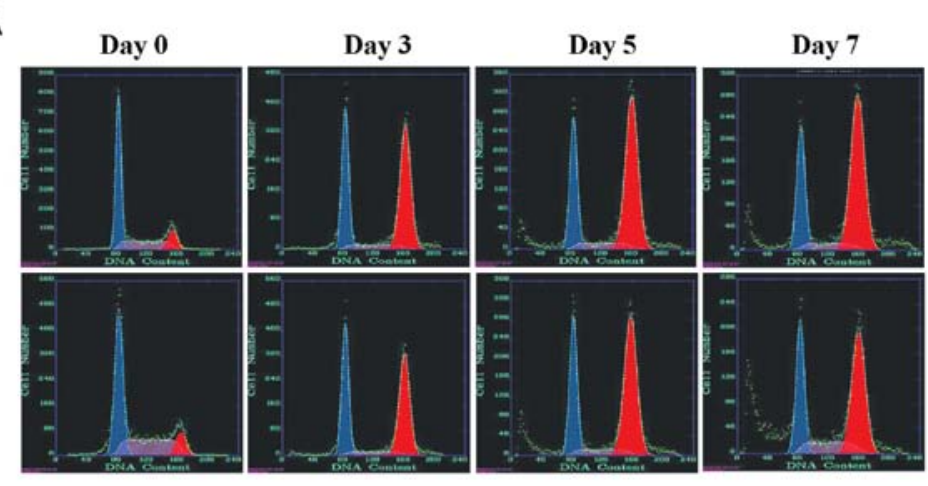

Days after $8 \mathrm{~Gy}$ irradiation

MCF-7-Pre

B

MCF-7-Pre

MCF-7-KD

C
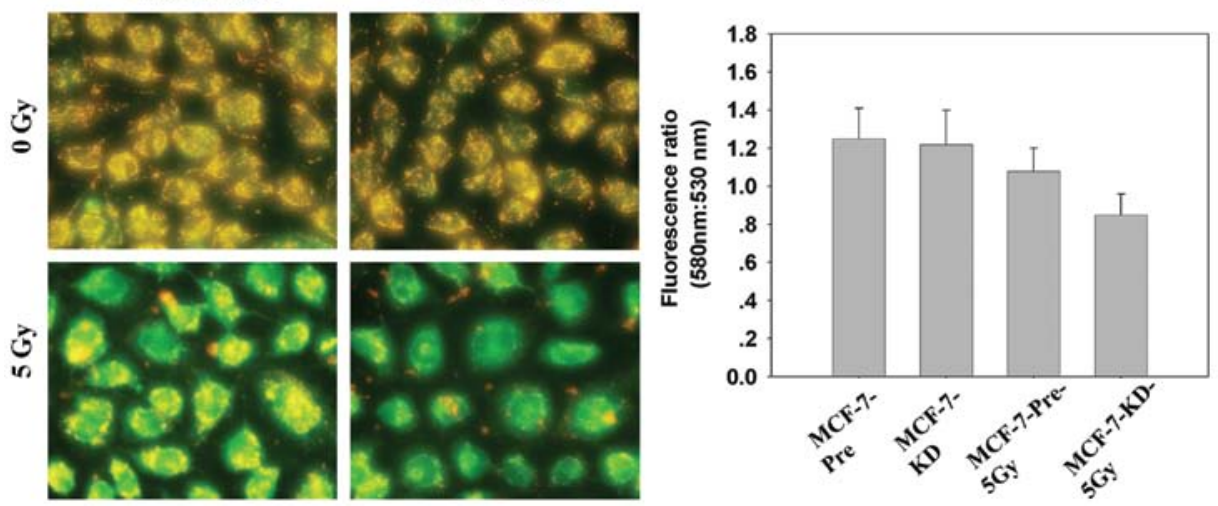

Figure 3. Bmi-1 depletion increased sub-G1 population. (A) Analysis of cell cycle distribution by flow cytometry. (B) Bmi-1 knockdown decreases mitochondrial membrane potential. Healthy mitochondria when it aggregates signal from JC-1 is depicted in red; when mitochondrial membrane potential collapses, signal corresponds to the green. Original magnification, $x 400$. (C) Quantitative results of fluorescence ratio $(580 \mathrm{~nm} / 530 \mathrm{~nm})$.

94.7\% of MCF-7-KD cells displayed $\gamma \mathrm{H} 2 \mathrm{AX}$ foci $(\mathrm{P}=0.005$; $\mathrm{t}$-test). Foci were no difference in 4 Gy and observed in $100 \%$ of both cells at 6 Gy. These data further demonstrated that Bmi-1 knockdown enhanced DNA DSBs. 


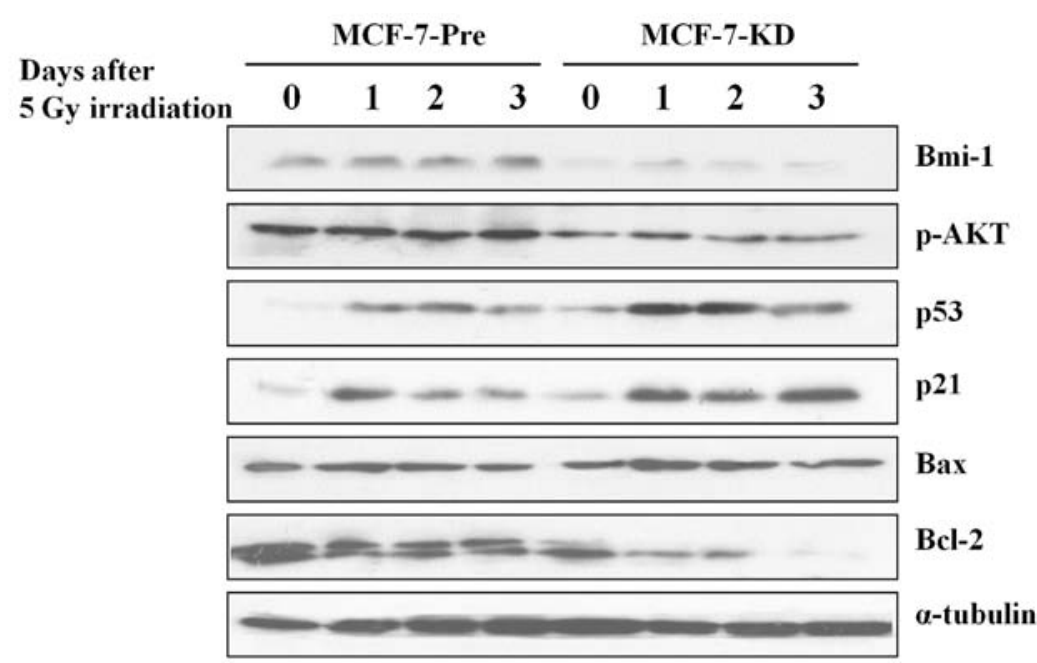

Figure 4. Western blot analysis of apoptosis related proteins. MCF-7-control cells and MCF-7-knockout cells were harvested on Days 0, 1, 2 and 3 after 5 Gy irradiation. Lysates were subjected to Western blot analysis with the labeled antibodies.

We next examined the kinetics of $\gamma \mathrm{H} 2 \mathrm{AX}$ in MCF-7-Pre and MCF-7-KD cells after irradiation. Fifteen minutes after 5 Gy, $95.7 \%$ of MCF-7-Pre cells and $100 \%$ of MCF-7-KD cells retained $\gamma \mathrm{H} 2 \mathrm{AX}$ foci (Fig. 2C). At $1 \mathrm{~h}$, foci remained in $82 \%$ of MCF-7-Pre cells and $100 \%$ of MCF-7-KD cells. At $6 \mathrm{~h}$, foci persisted in 59.7\% of MCF-7-Pre cells and in 83.3\% of MCF-7-KD cells ( $\mathrm{P}=0.001$; $\mathrm{t}$-test). After $20 \mathrm{~h}$, the number of foci for MCF-7-Pre and MCF-7-KD cells was 32.7 and $60.7 \%$, respectively $(\mathrm{P}<0.001 ; \mathrm{t}$-test). The results showed that the residual number of $\gamma \mathrm{H} 2 \mathrm{AX}$ foci in MCF-7-KD cells was significantly higher than that of MCF-7-Pre cells after irradiation. Thus, DSB repair capacity in MCF-7-Pre and MCF-7-KD cells was significantly different, indicating that Bmi-1 silencing deceased DSB repair capacity.

Bmi-1 knockdown promotes sub-G1 population and induces loss of mitochondrial membrane potential in irradiated MCF-7 cells. It has reported that Bmi-1 enhanced cell survival by altering cell cycle regulatory protein expression and inhibiting apoptosis (34). Thus, we investigate cell cycle distribution in MCF-7-Pre and MCF-7-KD cells after 8 Gy irradiation in different time points by FACS. Radiation induced G1-phase and G2-phase cell cycle arrest in both MCF-7-Pre and MCF-7-KD cells, but there was no significant difference between them. However, the percentage of the sub-G1 population, which is indicative of apoptosis, significant increased in MCF-7-KD cells (11.3 $\pm 1.1 \%)$ compared with MCF-7-Pre cells $(6.6 \pm 0.8 \%, \mathrm{P}<0.001$; ANOVA) (Fig. 3A). The data indicated that Bmi-1 knockdown was able to induce apoptosis in MCF-7 cells.

Next, we examined whether Bmi-1 inhibtion induced apoptosis in MCF-7 cells could be coincident with changes in mitochondrial membrane potential $(\Delta \Psi \mathrm{m})$. We used the fluorescent dye, JC-1, as an indicator of the energy state of the mitochondria. A loss in mitochondria membrane potential is indicated by a decrease in red/green fluorescence intensity ratio. As shown in Fig. 3B and C, Bmi-1 inhibition led to a rapid drop in mitochondrial energy, as reflected by a fluorescence shift from green (emission $530 \mathrm{~nm}$ ) to red (emission $580 \mathrm{~nm}$ ) by $24 \mathrm{~h}$ after $5 \mathrm{~Gy}$ irradiation. These data demonstrated that apoptosis induced by Bmi-1 inhibition combined radiation may be closely related to mitochondrial function.

Bmi-1 knockdown changes the signal pathway involved in apoptosis in MCF-7 cells. Then, we examined the levels of several apoptosis related proteins in MCF-7-Pre and MCF-7-KD cells. Western blot analysis showed that dramatically increased expression of p53, p21 and Bax protein, and decreased expression of $\mathrm{p}-\mathrm{AKT}$ and $\mathrm{Bcl}-2$ in irradiated MCF-7-KD cells compared with those in irradiated MCF-7-Pre cells (Fig. 4). This data indicated that Bmi-1 depletion sensitizes radiotherapy through activating apoptosis pathway.

\section{Discussion}

In this report, we present the first evidence that Bmi- 1 was correlated with radiation response in MCF-7 breast cancer cells. We showed that Bmi-1 overexpression developed radiation resistance, whereas Bmi-1 inhibition significantly increased radiation sensitivity with a DER of 1.40 by radiation clonogenic survival assay. It suggested that Bmi-1 might play an important role in the regulation of cellular response to radiation in MCF-7 cells. Thus, the results underscore the importance of Bmi-1 targeting in combination with irradiation in tumor therapy. In our previous study, we showed that Bmi-1 could enhance the invasion and metastasis of human breast cancer and predicts poor survival, Bmi-1 silencing reverses the expression of EMT markers and inhibits the Akt/GSK3 $\beta$ / Snail pathway (30). EMT promotes radioresistance in human tumor cells $(28,29)$, down-regulation of Bmi-1 could be a novel strategy to sensitize radiotherapy by reversing EMT in human breast cancer.

It is well known that DSBs are suggestive of critical lesions in DNA caused by ionizing radiation. DSB is the main mechanism of tumor cell death after irradiation, and some protein involve in DSB could be used as a prognostic predictor for cancer (35). The major cause of radiotherapy failure is the success of DSB repair in tumor cells, leading to prolonged 
tumor cell survival. Molecules that are involved in DSB repair may be potential prognostic markers for the prediction of radiotherapy outcome, and hence, for optimization of treatment. We found that Bmi-1 inhibition dramatically increased DSB and significantly decreased the rate of DNA DSB recovery induced by irradiation, suggesting a participation of Bmi-1 in DNA strand damage and repair. Studies have showed that increased p-Akt had been linked to decreased radiation responsiveness and inhibition of $\mathrm{p}$-Akt have radiosensitizing effects in various malignancies (36-39). Our study showed that p-Akt decreased after Bmi-1 inhibition, this might be one of reasons resulting in increased DSBs and decreased DSB repair in Bmi-1 knockdown cells.

If complete DNA damage repair fails, apoptosis is triggered for the elimination of damaged cells. We noticed that the number of apoptotic cells in Bmi-1 knockdown cells was much higher compared with that in the controls using FACS analysis. The mechanism of Bmi-1 inhibition combined radiation induced apoptosis is complex. A possible reason is that mitochondriadependent pathway for apoptosis was activated in response to combined Bmi-1 inhibition with ionizing radiation. In many tumor models of apoptosis, oxidative stress induced by ROS is a frequent mediator of apoptosis and produced massive cellular damage associated with lipid peroxidation, loss of mitochondrial membrane potential $(\Delta \Psi \mathrm{m})$, deletion of cellular antioxidants and Bax translocation to mitochondrial (40-43). In this study, we found MCF-7 cell silencing of Bmi-1 seems to be more susceptible to cell death with loss of $\Delta \Psi \mathrm{m}$ induced by irradiation (Fig. 3B and C). The underlying mechanism by which Bmi-1 inhibition induces loss of $\Delta \Psi \mathrm{m}$ in MCF-7 cells remains undefined. Several mitochondrial proteins, including Bcl-2 and Bax, possible play important roles in the process. During apoptosis, the imbalance between the expression of anti- and pro-apoptotic proteins is important. Our data showed that Bmi-1 inhibition enhanced proapototic p53, p21 and Bax expression but decreased levels of the antiapoptotic proteins p-AKT and Bcl-2 expression compared with control cells following irradiation.

In conclusion, we report the enhanced radiosensitivity of a breast cancer cell line after Bmi-1 inhibition using shRNA. The increased sensitivity was associated with increased DSBs and decreased DSB repair. We also showed that combination Bmi-1 inhibition with irradiation could induce apoptosis, collapse of mitochondrial membrane potential, elevated p53, p21, Bax expresseion, and deceased Bcl-2 expression. Our results suggest that Bmi-1 inhibition play an additive effect to radiation therapy in MCF-7 mammary carcinoma cells providing a novel target for radio-sensitizing breast cancer.

\section{References}

1. Jacobs JJ and van Lohuizen M: Cellular memory of transcriptional states by Polycomb-group proteins. Semin Cell Dev Biol 10: 227-235, 1999.

2. Schwartz YB and Pirrotta V: Polycomb silencing mechanisms and the management of genomic programmes. Nat Rev Genet 8: 9-22, 2007 .

3. Schuettengruber B, Chourrout D, Vervoort M, Leblanc B and Cavalli G: Genome regulation by polycomb and trithorax proteins. Cell 128: 735-745, 2007.

4. Spivakov M and Fisher AG: Epigenetic signatures of stem-cell identity. Nat Rev Genet 8: 263-271, 2007.
5. Rajasekhar VK and Begemann M: Concise review: roles of polycomb group proteins in development and disease: a stem cell perspective. Stem Cells 25: 2498-2510, 2007.

6. Haupt Y, Alexander WS, Barri G, Klinken SP and Adams JM Novel zinc finger gene implicated as myc collaborator by retrovirally accelerated lymphomagenesis in E mu-myc transgenic mice. Cell 65: 753-763, 1991

7. van Lohuizen M, Verbeek S, Scheijen B, Wientjens E, van der Gulden $\mathrm{H}$ and Berns A: Identification of cooperating oncogenes in $\mathrm{E}$ mu-myc transgenic mice by provirus tagging. Cell 65: 737-752, 1991

8. Jacobs JJ, Scheijen B, Voncken JW, Kieboom K, Berns A and van Lohuizen M: Bmi-1 collaborates with c-Myc in tumorigenesis by inhibiting c-Myc-induced apoptosis via INK4a/ARF. Genes Dev 13: 2678-2690, 1999.

9. Jacobs JJ, Kieboom K, Marino S, DePinho RA and van Lohuizen M: The oncogene and Polycomb-group gene Bmi-1 regulates cell proliferation and senescence through the ink4a locus. Nature 397: 164-168, 1999.

10. Dimri GP, Martinez JL, Jacobs JJ, et al: The Bmi-1 oncogene induces telomerase activity and immortalizes human mammary epithelial cells. Cancer Res 62: 4736-4745, 2002.

11. Guney I and Sedivy JM: Cellular senescence, epigenetic switches and c-Myc. Cell Cycle 5: 2319-2323, 2006.

12. Datta S, Hoenerhoff MJ, Bommi P, et al: Bmi-1 cooperates with H-Ras to transform human mammary epithelial cells via dysregulation of multiple growth-regulatory pathways. Cancer Res 67: 10286-10295, 2007.

13. Molofsky AV, Pardal R, Iwashita T, Park IK, Clarke MF and Morrison SJ: Bmi-1 dependence distinguishes neural stem cell self-renewal from progenitor proliferation. Nature 425: 962-967, 2003.

14. Raaphorst FM: Self-renewal of hematopoietic and leukemic stem cells: a central role for the Polycomb-group gene Bmi-1. Trends Immunol 24: 522-524, 2003.

15. Grinstein E and Wernet P: Cellular signaling in normal and cancerous stem cells. Cell Signal 19: 2428-2433, 2007.

16. Liu S, Dontu G, Mantle ID, et al: Hedgehog signaling and Bmi-1 regulate self-renewal of normal and malignant human mammary stem cells. Cancer Res 66: 6063-6071, 2006.

17. Vrzalikova K, Skarda J, Ehrmann J, et al: Prognostic value of Bmi-1 oncoprotein expression in NSCLC patients: a tissue microarray study. J Cancer Res Clin Oncol 134: 1037-1042, 2008.

18. Liu JH, Song LB, Zhang X, et al: Bmi-1 expression predicts prognosis for patients with gastric carcinoma. J Surg Oncol 97: 267-272, 2008

19. Wang H, Pan K, Zhang HK, et al: Increased polycomb-group oncogene Bmi-1 expression correlates with poor prognosis in hepatocellular carcinoma. J Cancer Res Clin Oncol 134: 535-541, 2008.

20. Chowdhury M, Mihara K, Yasunaga S, Ohtaki M, Takihara Y and Kimura A: Expression of Polycomb-group (PcG) protein BMI-1 predicts prognosis in patients with acute myeloid leukemia. Leukemia 21: 1116-1122, 2007.

21. Arnes JB, Collett K and Akslen LA: Independent prognostic value of the basal-like phenotype of breast cancer and associations with EGFR and candidate stem cell marker BMI-1. Histopathology 52: 370-380, 2008

22. Song LB, Zeng MS, Liao WT, et al: Bmi-1 is a novel molecular marker of nasopharyngeal carcinoma progression and immortalizes primary human nasopharyngeal epithelial cells. Cancer Res 66: 6225-6232, 2006.

23. Qin ZK, Yang JA, Zeng MS, et al: Expression and clinical significance of Bmi-1 protein in bladder cancer. Ai Zheng 27: 1327-1330, 2008 (In Chinese).

24. Glinsky GV, Berezovska O and Glinskii AB: Microarray analysis identifies a death-from-cancer signature predicting therapy failure in patients with multiple types of cancer. J Clin Invest 115: 1503-1521, 2005.

25. Mani SA, Guo W, Liao MJ, et al: The epithelial-mesenchymal transition generates cells with properties of stem cells. Cell 133: 704-715, 2008

26. Yang MH, Hsu DS, Wang HW, et al: Bmi1 is essential in Twist1induced epithelial-mesenchymal transition. Nat Cell Biol 12: 982-992, 2010.

27. Song LB, Li J, Liao WT, et al: The polycomb group protein Bmi-1 represses the tumor suppressor PTEN and induces epithelialmesenchymal transition in human nasopharyngeal epithelial cells. J Clin Invest 119: 3626-3636, 2009. 
28. Theys J, Jutten B, Habets R, et al: E-Cadherin loss associated with EMT promotes radioresistance in human tumor cells. Radiother Oncol 99: 392-397, 2011.

29. Kurrey NK, Jalgaonkar SP, Joglekar AV, et al: Snail and slug mediate radioresistance and chemoresistance by antagonizing p53-mediated apoptosis and acquiring a stem-like phenotype in ovarian cancer cells. Stem Cells 27: 2059-2068, 2009.

30. Guo BH, Feng Y, Zhang R, et al: Bmi-1 promotes invasion and metastasis, and its elevated expression is correlated with an advanced stage of breast cancer. Mol Cancer 10: 10, 2011.

31. Dimri GP, Itahana K, Acosta M and Campisi J: Regulation of a senescence checkpoint response by the E2F1 transcription factor and p14(ARF) tumor suppressor. Mol Cell Biol 20: 273-285, 2000.

32. Liu ZG, Chen HY, Cheng JJ, Chen ZP, Li XN and Xia YF: Relationship between methylation status of ERCC1 promoter and radiosensitivity in glioma cell lines. Cell Biol Int 33: 1111-1117, 2009.

33. Reers M, Smiley ST, Mottola-Hartshorn C, Chen A, Lin M and Chen LB: Mitochondrial membrane potential monitored by JC-1 dye. Methods Enzymol 260: 406-417, 1995.

34. Lee K, Adhikary G, Balasubramanian S, et al: Expression of Bmi-1 in epidermis enhances cell survival by altering cell cycle regulatory protein expression and inhibiting apoptosis. J Invest Dermatol 128: 9-17, 2008.

35. Yan SS, Liu L, Liu ZG, Zeng MS, Song LB and Xia YF: Expression and clinical significance of DNA-PKcs in nasopharyngeal carcinoma. Ai Zheng 27: 979-983, 2008 (In Chinese).
36. Kraus AC, Ferber I, Bachmann SO, et al: In vitro chemo- and radio-resistance in small cell lung cancer correlates with cell adhesion and constitutive activation of AKT and MAP kinase pathways. Oncogene 21: 8683-8695, 2002.

37. Liang K, Jin W, Knuefermann C, et al: Targeting the phosphatidylinositol 3-kinase/Akt pathway for enhancing breast cancer cells to radiotherapy. Mol Cancer Ther 2: 353-360, 2003.

38. Soderlund K, Perez-Tenorio G and Stal O: Activation of the phosphatidylinositol 3-kinase/Akt pathway prevents radiation-induced apoptosis in breast cancer cells. Int J Oncol 26: 25-32, 2005.

39. LoPiccolo J, Granville CA, Gills JJ and Dennis PA: Targeting Akt in cancer therapy. Anticancer Drugs 18: 861-874, 2007.

40. Lemasters JJ, Qian T, Trost LC, et al: Confocal microscopy of the mitochondrial permeability transition in necrotic and apoptotic cell death. Biochem Soc Symp 66: 205-222, 1999.

41. Kang YH, Yi MJ, Kim MJ, et al: Caspase-independent cell death by arsenic trioxide in human cervical cancer cells: reactive oxygen species-mediated poly(ADP-ribose) polymerase-1 activation signals apoptosis-inducing factor release from mitochondria. Cancer Res 64: 8960-8967, 2004.

42. Kim WH, Park WB, Gao B and Jung MH: Critical role of reactive oxygen species and mitochondrial membrane potential in Korean mistletoe lectin-induced apoptosis in human hepatocarcinoma cells. Mol Pharmacol 66: 1383-1396, 2004.

43. Park MT, Kim MJ, Kang YH, et al: Phytosphingosine in combination with ionizing radiation enhances apoptotic cell death in radiation-resistant cancer cells through ROS-dependent and -independent AIF release. Blood 105: 1724-1733, 2005. 